\title{
Impact of music therapy treatment on brain structure in early stages of Alzheimer's disease
}

\author{
By - Amisha Gupta - Student researcher of Biopsychology
}

\author{
Amisha Gupta \\ Laureate certified Student Researcher $\mid$ Davidson Young \\ Scholar - \\ ( http://yspw.davidsongifted.org/yspw/users/amishagupta) \\ http://peerknowledgesharing.com/amisha-gupta/) \\ NATS 2021 1st Place winner (..:4,@9: x ddmmdz a \\ https://youtu.be/9H-Q0e2PCAw) | \\ Youtube profile : \\ ( https://www.youtube.com/c/AmishaGuptaClassicalMusic) \\ LinkedIn : (h ttps://www.linkedin.com/in/amisha-gupta- \\ 3a6940201/) \\ Cherry Creek High School - Colorado \\ email: guptaamishagupta@gmail.com \\ Publication - \\ https://www.researchgate.net/publication/357735445 Title I \\ mpact of music therapy treatment on brain structure in ea \\ rly_stages_of_Alzheimer's_disease
}




\begin{abstract}
:
Aim:The Object of this research is to exhibit the potency and advantage of music therapy for Keepers and Alzheimer's disease (AD) people.

Methods: From 2020 to 2021, a research group scrutinized and investigated 32 persons with Alzheimer's Disease (ICD-10) medicated by general practitioners, music psychotherapists and neurologists through MMSE. The musical brain analysis with medical results of the patients was estimated and also the response of the tutors and the Patients of Alzheimer's were Noted. In Family or Personal Sessions, musical instruments were added. The MMSE was used for the patient's Evaluation Purpose. Under Neurologist's Supervision, the examination was re-conducted every six months. Finally, 31 patients withAlzheimer's Medication were Observed And calculated.

Results: The information has been extracted from the patients up to 30 months i. e from the start of the session to the end. As the Above discussion, the Results of the total 35 Patients withAlzheimer's Disease observed by MMSE are 12 patients were in Severe or Serious condition,20 were in Moderated Conditioned And 5 persons are with Mild Condition of AD. After 30 months, it is observed that 33.50\% (12 Patients) had Alzheimer's disease Mildly. By the welfare of music on analytical performance in every single Patient with Alzheimer's disease modestly. From the initial $60.41 \%$ (20 patients) with modest AD,51.42\% (15 patients) were observed with a number imputable to the sum of the patients who developed from Serious AD and whose who changed from Modest to Mild AD, Well-being by the Treatment.Lastly, before the treatment, we had 15 patients $(40.15 \%)$ with serious AD, which has been changed to $21.22 \%$ (10 patients) with serious AD and they were Observed And evaluated.
\end{abstract}

Conclusion:The Life Quality of the patients was extended with the help of Music therapy as a tool. The effective report on the treatment of AD is obtained from the great collaboration of research

Keywords: CareGivers, Alzheimer's Disease Patients, Improvement of Cognitive Impairment, MusicTherapy,

1. Introduction:Dementia is a combination of symptoms that impact remembering, cognition, behavior, and social intelligence to the point where they interfere with everyday activities. It does not represent a single condition, but it may be caused by a combination of diseases. The most common source of progressing dementia is Alzheimer's disease in the elderly[1]. Dementia has been classified into several categories. Vascular Dementia, Alzheimer's disease, Lewy Body Dementia, Mixed Dementia and Fronto Temporal Dementia, are all gradual as well as permanent, however, there are some Alzheimer's circumstances which are transient (immune, nutritional, and metabolic disorders, infections, deficiencies, subdural hematomas, medication side effects, anoxia, poisoning, hydrocephalus and brain tumors). Adjustable (alcohol use, exercise, Diet depression, cardiovascular risk factors, smoking, diabetes, Nutritional deficits, sleep apnea) and irreversible (Down syndrome, family history, age,) risk factors for dementia have been identified [2].Symptoms of dementia differ depending just on etiology, however, some frequent ones include. Modifications in cognition (disorientation,memory loss, and,confusion for example)communication difficulties, visual and spatial ability, thinking, and handling complicated tasks and planning, coordination and motor function difficulties) Depression, Personality changes, anxiety, and improper behavior are all examples of psychosocial alterations.Hallucinations, paranoia,behavior, andanxiety) [1] [2]. Dementia, and specifically Alzheimer's disease, has been regarded as a fatal disease due to infections, poor nutrition, diseases, inability to manage, loss of autonomy, incapacity for personal safety, care for oneself, the emergence of significant comorbidities such as death, and cardiovascular disease.Dementia is a difficult disease to recognize. It is based on the medical examination and medical history and symptoms. Those concerned, such as family members or carers, are most likely to provide the information. Dementia cannot be diagnosed using a single test [1].Alzheimer's disease is diagnosed clinically (clinical criteria based on ICD-10, DSM-V). Neuropsychological testing, Cognitive, Brain Scans, Neurological evaluation, Psychiatric test, andLaboratory test Evaluation are also included in the diagnosis algorithm. To rule out alternative possibilities, brain scans, CT scans, EEG, or lumbar punctures are usually performed. At least one of the various cognitive tests, such as with the MoCA, Blessed 
Dementia Information- Recollection scale (BDS-IMC),GPCOG, SLUMS, MMSE, Mini-Cog, andMIS cognitive tests, should be employed and during evaluation [2] [3].The function of dementia caregivers, whether usually consists of relatives or cares from the outside family milieu, is critical in dementia. Aggression,frustration, insomnia and anxiety, are common symptoms, and alterations in individuals' social, professional, and family lives are common.Caregivers had significant depression levels and negative feelings, as well as a poorer experience of levels of happiness, friendly company, limited social activities, and just a reduced sense of happiness in their lives.Despite indicating a worsening state of health, over-the-counter drugsand overuse of health-care services [4].Alzheimer's disease is a big source of worry for patients in the United States.Not just financially, and also psychologically or above time, cares. According to a 2016 study.Caregivers of patients with Alzheimer's disease used to have a 30 percent worse ability to care for them, according to the study should spend their money on a healthy diet.Further observation is many members of the family including acquaintances of people with the condition experience significant financial hardship as a result of channeling entire funds and pension towards meeting the needs of the disabled, compromising their own feeling of individual financial stability. Furthermore, by providing free, non-remunerative work. According to one study, caregivers spent an average of 34.3 hours per week helping such patients in 2013 [5]. Often these dementias are incurable, however with the correct medication, such as Cholinesterase Inhibitors, Meantime, and other antipsychotics such as SSRIs, SNRIs, and new generation antipsychotics for parkinsonism, agitation, allusions, sleep disturbances, and depression, we can manage as well as alleviate their own symptoms, and improve the cognitive and functional status of patients [1] [2].Occupational therapy, environmental modifications, and other non-drug ways to treat dementia symptoms but also behavior problems may be used first.Clarifying the chores is one of the misuses. In addition, we can offer other options treatments which may aid in the reduction of anxiety as well as the promotion of relaxation. Music therapy, light exercise, and watching family videos are all recommended for patients with Dementia.Pet therapy, Aroma and Massage treatment, with Art therapy, are the four types of therapy [2].My research work in this article is mostly focused on alternative therapeutics approaches, with a focus on using music therapy as a tool for stress reduction.However, researchers also looked at the mental and behavioral symptoms of dementia patients assess when music has the capacity to help a condition of the patient therapy, as well as the effect on their overworked careers.Music therapy interventions are frequently employed as a nonpharmacological treatment for Alzheimer's disease symptoms in perception and behavior. Despite their extensive use, there is little evidence of their usefulness.Inside the literature, there is still a lot of confusion.Music is among the oldest forms of healing. Pythagoras considered music to be a form of art.Proportions are identical to brain proportions, and as a result, they vary with the aid of[6] [7] musicWhenever the equilibrium between extremes in the soil is disrupted, mental diseases occur, as well as discordances in the cosmos, soul, and music emerge, wherever music does have the power to bring a troubled soul back into the world.Plato claimed the music being given to man to not entertain his sense, but rather to alleviate his mind and body's afflictions [8] [9] [10]. Aristotle stressed music's affective brain and impact on emotions affects people's feelings [11] [12] [13]. Tibetan monks have discovered that reciting basic sounds may alter their state of mind, boost their sense of well-being and raise their state of consciousness. Music therapy was originally used in the United States during World War I.Soldiers at veterans' hospitals receive assistance. The American Music Therapy Association is a non-profit organization dedicated to music therapy.The American Music Television Association (AMTA) was formed in 1998 as a result of the merging of the American Music Television Association (AMTA) and the American Music Television Association (AMTA).The National Music Therapy Association (established in 1971) and the Therapy Association (formed in 1971) are two organizations dedicated to music therapy (1950).Its goal is to improve public knowledge of the benefits of music therapy while also increasing access to high-quality music therapy services [14].According to modern music therapists, disease originates whenever the mind, body, and spirit's many forms of energy resonate at improper frequencies [15].Therapists help persons with dementia, Parkinson's disease, postoperative and chronic discomfort from diseases including cancer but also osteoarthritis, and during physical and neurological rehabilitation [16] [17]. In reality, there are now centers where women can be musically prepared during, throughout, and then after labor [18].Several treatment strategies are effective for different numbers of people with Alzheimer's disease including its caregivers, who really are mainly family members [19] [20]. 
2. Aim: The goal of this retrospective study is to enhance the feasibility of music therapy in Alzheimer's diseases as well as the possible advantages to their caretakers.

3. Materials and Methods: During the biannual 2020-2021 period, 35 patients having Alzheimer's disease (ICD-10 symptoms) were investigated, 19 women and 16 men (ages 59 to 87), with an average age of 73 years. It is indeed worth noting that another one of our initial 35 Alzheimer's disease, a 73-yearold man, died from pneumonia throughout our study, leaving us with 35 patients to complete our treatment strategy. A neurologist, a physical therapist, and just a music psychotherapist-psychologist made up this study's research group. A neurologist taking Rivastigmine, antidepressants, or Donepezil, or a mixture of the two, to all patients 6 months before and throughout the research.His neurologist advised patients and caregivers to begin music therapy sessions, which resulted in all of the patients participating in the study. Participants were selected at random, independent of their age, socioeconomic status, educational level, or any medical conditions. Informed consent was four components out by the competent AD patients or caregivers individually, on whatever it contains. The examiners gathered the patients' medical and social histories, and also their musical characteristics (their musical tastes through infancy to the time they fell ill). The following items were included in the comprehensive completion of the music characteristics:

1) Identification card (generic information about the examinee) and indeed the stage of the disease to whom the patient belongs.

2) Receptivity to Musical (overall music susceptibility, susceptibility to specific musical tones, responsiveness to specific forms of music)of music, as well as instrument kinds).

3) The healer's perspective on the therapeutic use of music.

4) A healthy environment (ancestors,family, prior personal experiences, etc.)a contemporary music environment).

5) Preliminary Questionnaire for Music Therapy.

6) The discussion of music culture is held.

There was the music group therapy, which included a variety of musical instruments (bogo, piano, scrapers, drums, maracas, and claps). Groups and meetings were held during the programs. Such meetings took place 2 - 3 times a week, in either individual therapy or even in a group meeting that lasted no more than an hour.

The following have been the components of the music therapeutic process:

1. Listening to music.

2. Singing.

3. Improvising.

4. Talking and listening to music.

Our music therapist was using the piano in group sessions, so each patient played one of the musical instruments of his choice. With such a selection of a variety of musical excerpts (length 4 - 6minutes each with its own maximum number of 10 music samples), the therapist determined a musical topic that would be nearly similar to the musical characteristics of those attending. A description piece, a rhythmic work, a melodic work, workplace noises, or a modern musical topic, for example. The music therapist started by playing multiple chords on the piano, and one of the patients replied by performing his preferred musical instrument.The same procedure was used for the answers of three, six, and ultimately the session. Their careers were active all through the exercise, clapping their hands in time with the music. Rhythmic was 
indeed the music connection that connected patients (previous musical experiences) with their caretakers.During individual sessions, the music therapist selected a song that was current with the patient's creative phase based on the patient's music characteristics.Her therapist sang and performed, halted, and also was interpreted again.This patient (singing or, if he couldn't, chanting) Then both came to a halt.There was a conversation that followed. The music therapist questioned the patient whether the song remembered him of everything if it made him think if it made him feel good or bad (attempt) to remember).The Mental Status Examination Survey was used to classify and evaluate the course of disease of participants, as shown in Figure 1 (Brain Functioning Interview Checklist). The following factors are examined in this standardized test: direction, processing, and attentiveness but also arithmetic, recollection, including speech), which would be defined by the following characteristics:a calibrated scale that divides individuals into groups based on the severity of their ailmentFigure 2 illustrates this. Every 6 months, the aforesaid Mini-mental state Test was repeated there under the guidance of our team's neurologist.In terms of music therapy for Alzheimer's patients as well as its effects on caregivers, we looked at whether personal relationships are enhanced and emotional bonds were reinforced, but also caregivers' everyday interactions and patients in practical issues. A structured interview was conducted for each patient's primary caregiver, a total of 29 careers.

Mini-Mental State Examination (MMSE)

\begin{tabular}{|c|c|l|}
\hline $\begin{array}{c}\text { Maximum } \\
\text { Score }\end{array}$ & $\begin{array}{c}\text { Patient's } \\
\text { Score }\end{array}$ & \multicolumn{1}{|c|}{ Questions } \\
\hline 10 & & "Where are we now " State? Country? Town/City? Hospital? Floor?" \\
\hline 10 & & $\begin{array}{l}\text { The examiner name three unrelated object clearly and slowly, then the } \\
\text { instruction asks the patient to name all three of them }\end{array}$ \\
\hline 2 & & Make up and write a sentence about anything's \\
\hline 2 & & Please copy this picture \\
\hline 1 & & Write instruction in " close your eyes" \\
\hline 10 & 35 & Show the patient two sample object \\
\hline
\end{tabular}

Figure 1: Questionnaire for a MMSE. Note: Figure 1 depicts the MMSE tests, a 30-point questionnaire widely used in clinical settings to screen for Dementia as determine the severity of cognitive impairment. McHugh,"Mini-mental state: A practical tool for assessing the cognitive condition of patients," according to the press release "The doctor."

\begin{tabular}{|c|c|l|l|}
\hline Score & Impairment Levels & Psychometric Evaluation Formal & \multicolumn{1}{|c|}{ Day-to-day operation } \\
\hline 25-30 & $\begin{array}{l}\text { Questionable } \\
\text { Importance }\end{array}$ & $\begin{array}{l}\text { If there is clinical problem with } \\
\text { cognition, a systematic } \\
\text { examination of cognition may } \\
\text { also be beneficial. }\end{array}$ & $\begin{array}{l}\text { Clinically severe yet modest } \\
\text { deficiencies are likely to affect } \\
\text { mainly the most demanding } \\
\text { everyday activities. }\end{array}$ \\
\hline 20-25 & Mild & $\begin{array}{l}\text { Formal evaluation may also be } \\
\text { beneficial in determining the } \\
\text { pattern and level of impairments. }\end{array}$ & $\begin{array}{l}\text { Score supervision, support, and } \\
\text { assistance may be required if the } \\
\text { effect is significant. }\end{array}$ \\
\hline $10-20$ & Moderate & $\begin{array}{l}\text { Formal evaluation may be } \\
\text { beneficial. Whether there are any } \\
\text { specific clinical signs or } \\
\text { symptoms, }\end{array}$ & $\begin{array}{l}\text { If there is a clear impairment, 24- } \\
\text { hour supervision may be required. }\end{array}$ \\
\hline $0-10$ & Severe & $\begin{array}{l}\text { It's unlikely that the patient will } \\
\text { be able to be tested. }\end{array}$ & $\begin{array}{l}\text { Significant disability will almost } \\
\text { certainly necessitate 24-hour } \\
\text { supervision and ADL assistance. }\end{array}$ \\
\hline
\end{tabular}


Figure 2. An illustration of how to interpret the results of the MMSE test. Note: In the severity stage of Dementia, Figure 2 displays the interpretation of the MMSE scale scores and their significance. "Minimental state: A practical tool for grading the cognitive state of patients for the clinician," Folstein MF, McHugh PR, Folstein SE.

4. Results: The patients were followed for a total of 35 months. We obtained the following data at the start and end of the sessions, which are displayed in Table 1 and Graph 1 and Graph 2. According to the MSE diagnostic but also stage scale of the disease, 5 patients (10\%) had 20 patients $(65 \%)$ had a moderate mental impairment, mild mental impairment, and 10 patients (35.34\%) had severe mental cognitive deficits in a total of 35 patients with AD.After 35 months, a total of 35 patients had a mild mental illness ( 65 percent), the number resulting from the benefit of improving brain abilities in patients with moderate AD. One patient died meanwhile due to pneumonia and can be evaluated, not having completed the program, 11 patients used to have a mild mental illness (65 percent), quantity resulting from the benefit of improving brain abilities in patients with moderate AD. Out of the initial 20 (65 percent) patients with moderate disease, 15 (50 percent) had moderate mental retardation, a number contributed to the total amount of patients who improved from severe disease and those who were transferred, likely to benefit from therapies, from moderate AD disease to mild AD mental defect based on the MMSE scale.Finally, 10 patients with severe AD illness (20 percent) were examined, while 15 patients (35.45 percent) have serious psychological impairment prior to therapy, but one patient with severe AD disease, a 73-year-old man, died before the study was completed. There was an improvement in everyday interaction, a reduction in stress, and a strengthening of emotional relationships with patients among caregivers who were asked in person about the treatment's benefits. As a result, we believe that careers, as crucial members of the patient-caregiver team, benefited indirectly from our intervention.

\section{Statistics:}

Table 1 shows the absolute numbers of follow-up AD patients before and after music therapy intervention.

\begin{tabular}{|l|l|l|l|}
\hline Brain Level & $\begin{array}{l}\text { Severe Alzheimer's Disease } \\
\text { (Cognitive Impairment) } \\
\text { (MMSE Score:1-10) }\end{array}$ & $\begin{array}{l}\text { Moderate Alzheimer's } \\
\text { Disease Cognitive } \\
\text { Impairment } \\
\text { Score:11-20) }\end{array}$ & $\begin{array}{l}\text { Mild Impairment Cognitive } \\
\text { InMSE } \\
\text { Alzheimer's Disease }\end{array}$ \\
\hline Before therapy & & & \\
\hline Men & 5 & 11 & 2 \\
\hline Women & 7 & 10 & 3 \\
\hline After Therapy & & & 6 \\
\hline Men & 3 & 8 & 7 \\
\hline Women & 4 & 9 & \\
\hline
\end{tabular}

Note. Table 1 displays the final follow-up data for patients with Alzheimer's disease, expressed as absolute numbers of patients. before and after music therapy participation, they belonged to various phases of Alzheimer's disease severity. Patient $(* 1)$ who has passed away 


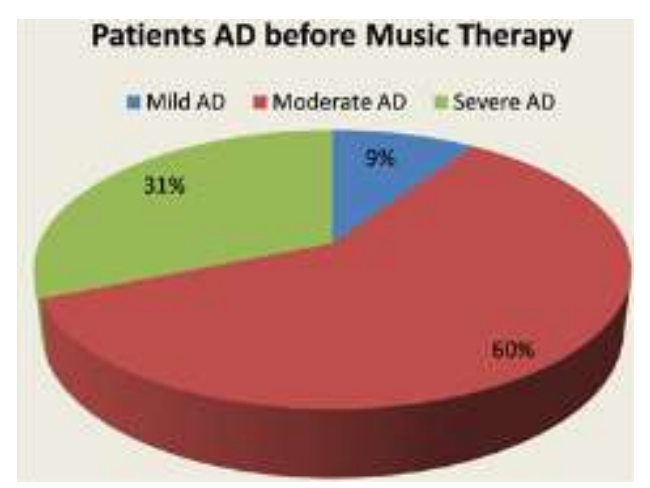

Graph 1: Before beginning music therapy, patients (AD).

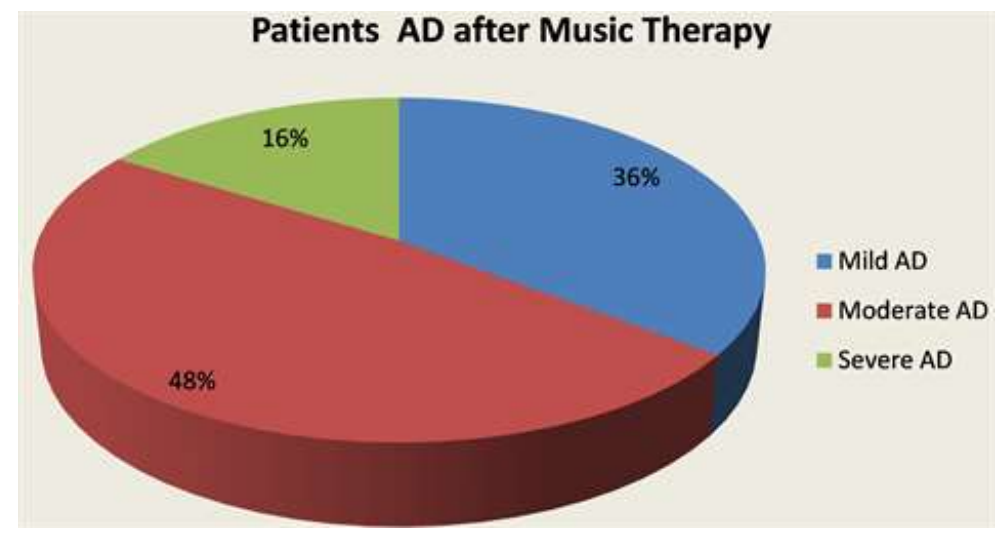

Graph 2: After the Music-Therapy therapeutic intervention, patients (AD).

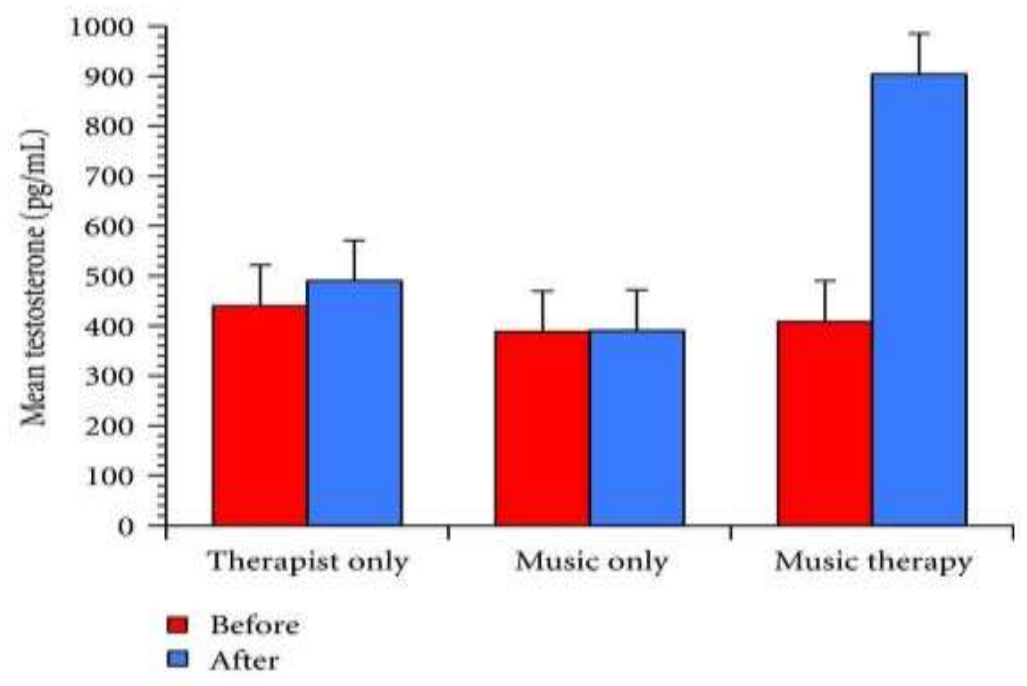

\section{Mean of Graph1 and Graph2}

Cases of severe mental disabilities exhibited a considerable shift (reduction of nearly 75\%) in Graph 1 and Graph 2, as some benefitted from the treatment and progressed to the level of Moderate AD, while one of those patients died. Patients with mild AD exhibited an increasing trend in the percentage of patients throughout this stage (up 36\%), which is attributed to better brain ability in patients with mild to 
moderate $\mathrm{AD}$ who crossover to this level after music therapy.Moreover, the percentage shift in patients with mild to moderate mental retardation (Moderate AD) is particularly noteworthy, with a decrease in the percentage of patients following music therapy of $20 \%$, indicating that they benefited significantly from music therapy.

6. Discussion: Alzheimer's disease is a brain degenerative illness that causes progressive deterioration of superior mental processes, with huge economic and social consequences.It leads to the gradual deterioration of memory, cognition, and conduct. It was named after Aloes Alzheimer's, a German physician who first reported the symptoms in 1907. Roughly 60 million individuals worldwide suffer from dementia, with nearly 10 million new cases diagnosed each year.Alzheimer's disease is a common type of dementia, accounting for $70 \%$ to $80 \%$ of cases. Dementia is a leading source of disability and dependency among the elderly around the world [1] [21]. The disease is most common in persons over the age of 65 , but it can also happen in people between the ages of 40 and 50. Until quite recently, theoretically, dementia in persons over 70 was caused by atherosclerosis. "Senile dementia" is a disease of the brain's blood vessels. This mindset began to change [1] [21]. The disease's cause is unknown, however environmental and genetic factors have been implicated.There are several variables to blame [22] [23] [24].So there's no conclusive proof that most of the putative Alzheimer's medical uses (e.g., brain vasodilators like Naftidrofuril or massive doses of vitamins B, C, and E, etc.) have had any specific benefit [25] [26] [27] [28] [29].According to those research [30] [31], pharmacotherapy seeks to improve perception as well as decrease nevertheless, symptoms; the therapeutic compounds provide only limited advantages to patients. (Cholinesterase inhibitors (Rivastigmine,Galantamine, Donepezil) and Memantine may help to slow or stop the progression of the disease [32].In particular, the new Memantine appears to just be beneficial in terms of mental ability at all stages of the disease, particularly in individuals with moderate mental disability [33].SSRIs have been proven to slow down the progression of initial mental deterioration in Alzheimer's disease, and in the absence of anxiety. It is most likely owing to SSRIs' effect on the development of -amyloid precursor protein, which is a histological basis of Alzheimer's disease. Although SSRIs are less successful in treating depression by Alzheimer's disease, they may well have clinical potential for treating as well as delaying Alzheimer's disease, especially if treatment is initiated early [34].In a meta-analysis, risperidone and SSRIs were found to be useful in treating stress caused by Alzheimer's disease, however, the results did not support haloperidol.Due to a decrease in efficacy, the administration was discontinued [35].Music therapy is a versatile and accessible tool that can be utilized on patients in a variety of settings in a number of different ways In 2015, Raglio and Oasi identifies three clinical approaches:Music therapy, music listening, and music-based interventions are all examples of music therapy.The Association Of Canada of Music Therapists defines music therapy as"The process through which experienced personnel use music to enhance their work."to foster therapeutic interactions with patients to promote economic growth, happiness, and well-being.Music therapy uses a modeling approach to incorporate the important feature of client/therapist contact which could include aggressive (improvisation, song, clapping, dancing) or passively (interested listening to music to identify the aspects it contains) methods. The construction of a therapist-to-patient playlist that can be customized or picked by the therapist is one method of listening to music.According to recent research, individualized decisions are more useful in Alzheimer's disease through increasing memory retrieval, as evidenced by multiple studies [35] [36] [37] [38]. The use of songs alone without the assistance of a therapist to promote patients is indeed known as generalized music treatment. Active or passive protocols can be used in these ways. According to a study [39], "background music is utilized to inspire expressions, memories, or to increase relaxation.".The foreign literature frequently verifies and expands on the findings of our research. The basic conclusion is that music has a wide range of effects on people with dementia. First and foremost, there is evidence that music memory can be preserved in patients with Alzheimer's disease, even when they have a sharp decline in perception, as reported in a survey [40]. This one is thought to be because musical neural networks are not like standard temporal memory-related monasteries [41] [42]. Which are continued till the disease has progressed to the advanced stages [43].Not only does music engage a "music region" in the brain, but it also activates a larger network. Viewing familiar music (including such famous traditional songs, children's music, etc.). This musical human memory contained 
regions within the songs, which were popular at the time outside the reticular formation, and also frontal and parietal sections, as well as frontal and parietal sections, also verified by other research [41] [42] [43]. Such dispersed connections may make it possible for music capabilities to be resurrected. Jacobsen [43] also employed PET methods in a study that establish the degree of the damage.various parts of music listening were affected with Alzheimer's disease histology, including such in terms of amyloidal buildup and gluconeogenesis in comparison to the rest of the brainThose locations were shown to be less pathogenic.People's choices ability to remember music makes it just a one-of-a-kind stimulation that efficiently stimulates people with dementia.Alzheimer's. Statistical tests also show that the total impact of music and music therapy is positive is especially notable, despite the fact that the amount of the effect is inconsistent in every study [44]. The beneficial effects of interventions based have been established across several existing literature.on the range of diagnostic groups, four of which have been explicitly targeted centered on using musical exercises with dementia patients [45]-[51].Alzheimer's disease was also the subject of research. For instance, studies on. Music therapy in care homes and the health of their families was discovered to be helpful.Therapy considerably improved visit satisfaction. He also discovered that the song and rhythm experience elicited the most participation [52].Patients with Alzheimer's disease are fully aware that they are prone to depression. Successful engagement in music has been proven in studies to alleviate depression, frustration, and feelings of failure [52].Furthermore, research appears that the stimulus of rhythm, harmony and a well-known tune stimulates the elderly to gravitate toward music. Individual or group music therapy can give stimulation and sensory stimulation, as well as maintain current capacity that increases the quality of life [53].The benefits of music have indeed been documented to be successful in decreasing agitation/aggression, agitation, abstract thinking, repeating voices, irritability, hallucinations, and anxiety in the majority of research [54]-[66].Researchers have suggested that playing even recorded music (chosen based on personal tastes) makes noise exposure more recognizable but also regular, as well as providing a link to warm memories from of the previous that inspired soothing feelings in the current [66] [67].Music improves orientation, memory recall, commitment and engagement, as well as social conduct [53] [68]-[73].Playing recorded music also helps to generate a relaxing mood [70]. It's worth noting that the session's framework, as well as the treatment model, are both remarkable.Participation and sociality were promoted by musical activities [70]. Therapists are people who work with music.pre recorded music as a curtain so over terrifying but also mysterious sound in the room[71] the climateOf addition, there are some concerns about music's usefulness.therapy. Studies have demonstrated that, despite the fact that music has a huge impact on people's lives. It could not, however, significantly lower the frequency of aggressive behavior[73] Behavior patterns. There were also no differences in the levels of excitement and restlessness discovered by the researchers contrasting the absence of music with the presence of music. They rationalized this by stating that the music in their study was not chosen based on the composition of the participant' unique preferences [58].Some therapists discovered that individuals respond more appropriately to practices when they were given exercise that instead of music therapy with the song [74] [75].A recently Spanish analysis revealed that careers but also family members of Alzheimer's patients saw a $50 \%$ increase in their social conduct [76].A study of available literature from 2008 to 2018 comparing various music therapy approaches found that, regardless of the technique utilized, forms that incorporated a personalized selection of music produced the best effects [77].Active music therapy may be able to engage people in social engagement, resulting in immediate advantages. Background music might also be a soothing strategy having long-term benefits to human health. The results of this study imply that music therapy could be employed in a number of ways of helping these people change their behavior cognitive perception [77].Despite the inconsistent outcomes there in the literature, many academics including clinicians advocate for using music in clinical settings, as suggested by different studies [78] [79].

7. Conclusions:The following are the main characteristics of the current study where we noticed that Music Therapy assisted with Alzheimer's disease:

1) This disease phase with which our patient belongs, as well as the MMSE.

2) The ability to put basic thoughts into practice. The development of current memory in terms of real expertise, such as food preparations and memory recall, that aids patient pleasure. 
3) With terms of collecting as well as interpreting information received, accelerating the pace of detecting through eyes and listening.

4) Psychological intimacy and pleasant changes in mood whenever partners, as well as families, enjoy their innovative music experience. Stress reduction and depressed behavior reductionReduce caregiver worry and stress.

Long-term monitoring through multiple sources (general practitioner, caregivers, psychologist-music therapist) has been used to synthesize distinct addictions while non-addicts, as well as the impact of music therapy on Alzheimer's patients were established.The Mini-Mental State Investigation, conducted under the supervision of a neurologist, was perhaps the most precise inspected.The original study flaws also include the development of an emotional bond between both the research group as well as the intervention team, which reduces this same observation's consistency, the incapability to document the impact of music therapy on displays of emotion with a consistent tool, and indeed the lack of a patient group receiving the medicine. As a witness, for a length of time without engaging in music therapy sessions.Music therapy is a valuable tool for enhancing the quality of life of both people with chronic disease and their careers, and it accomplishes this by addressing mental, physical, emotional, and social goals. The effective collaboration of the research-therapy team is responsible for the intended result in the treatment of Alzheimer's disease. It has been discovered that while therapy does not cure Alzheimer's disease, this does improve the quality of life and serves as a crucial communication tool.

\section{References:}

[1] World Health Organization (2021) Dementia. https://www.who.int/news-room/fact-sheets/detail/dementia

[2] Mayo Clinic (2021) Dementia.

https://www.mayoclinic.org/diseases-conditions/dementia/symptomscauses/syc-20 352013

[3] Atri, A. (2019) The Alzheimer's Disease Clinical Spectrum: Diagnosis and Management.

Medical Clinics of North America, 103, 263-293.

https://doi.org/10.1016/j.mena.2018.10.009

[4] William, H., Levine, E., Brown, L., et al. (1987) Psychosocial, Social and Health

Consequences of Caring for a Relative with Senile Dementia. Journal of AmericanGeriatrics Society, 35, 405-411.

https://doi.org/10.1111/j.1532-5415.1987.tb04661.x

[5] Grabher, B.J. (2018) Effects of Alzheimer's Disease on Patients and Their Family. Journal

of Nuclear Medicine Technology, 46, 335-340.

https://doi.org/10.2967/jnmt.118.218057

[6] Sakellarion, G. (1962) Pythagoras: The Century Master. Ideotheatron Press, Athens.

[7] O’ Oliver, F. (1995) The Golden Verse of PYTHAGORAS. Solar Press, New York.

[8] Francis, M.C. (1945) Plato: The Republic of Plato. Oxford University Press, New York

[9] Kraut, R. (1992) Cambridge Companion to Plato. Cambridge Press, London.

https://doi.org/10.1017/CCOL0521430186

[10] Vlastos, G. (1981) Platonic Studies. 2nd Edition, Princeton, London.

[11] Gerald, F.E. (1967) Aristotle, Poetics. University of Michigan Press, Ann Arbor.

[12] John, H. (1947) Aristotle: The "Art" of Rhetoric. Classical Library, Loeb.

[13] Else, G.F. (1963) Aristotle's Poetics: The Argument. Harvard University Press, Cambridge.

[14] AMTA: American Music Therapy Association, Silver Spring, Maryland USA.

[15] Wheeler, B. (1981) The Relationship between Music Therapy and Theories of Psychotherapy.

Music Therapy. The Journal of the American Association for Music

Therapy, 1, 9-16. https://doi.org/10.1093/mt/1.1.9

[16] Ridder, H.M. (2002) Singing in Individual Music Therapy with Elderly Persons Suffering

from Dementia. Music Their World.

[17] Griffith, R.W. (2001) Music Making Helps Parkinson's Patients. Health Age, 1, 3-5.

[18] Steele, P.H. (1988) Children's Use of Music Therapy. In Music Therapy One Day 
Conference: Music and the "Cycle of Life".

[19] Woodcock, J. (1987) Towards Group Analytic Music Therapy. Journal of British

Music Therapy, 1, 16-22. https://doi.org/10.1177/135945758700100105

[20] Brotons, M. and Marti, P. (2003) Music Therapy with Alzheimer's Patients and

Their Family Caregivers: A Pilot Project. Journal of Music Therapy, 40, 138-150.

https://doi.org/10.1093/jmt/40.2.138

[21] Folstein, M.F., Folstein, S.E. and McHugh, P.R. (1975) Mini-Mental State: A Practical

Method for Grading the Cognitive State of Patients for the Clinician. Journal of

Psychiatric Research, 12,189-198. https://doi.org/10.1016/0022-3956(75)90026-6

[22] Adams, R.D. and Victor, M. (2000) Principles of Neurology. 7th Edition, McGraw-

Hill Professional, Boston.

[23] Bradley, W.G., Daroff R.B., Fenichel, G.M., et al. (2004) Pocket Companion to

Neurology in Clinical Practice. 4th Edition, Elsevier, Butterworth-Heinemann.

[24] Beers, M.H. and Berkow, R.D. (2018) The Merck Manual of Diagnosis and Therapy.

20th Edition, Merck Editor, Kenilworth.

[25] Zhang, D.M., Ye, J.X., Mu, J.S., et al. (2017) Efficacy of Vitamin B Supplementation

on Cognition in Elderly Patients with Cognitive-Related Diseases. Journal of Geriatric

Psychiatry and Neurology, 30, 50-59.

https://doi.org/10.1177/0891988716673466

[26] Wang, W., Li, J., Zhang, H., et al. (2021) Effects of Vitamin E Supplementation on

the Risk and Progression of AD: A Systematic Review and Meta-Analysis. Nutritional

Neuroscience, 24, 13-22. https://doi.org/10.1080/1028415X.2019.1585506

[27] D'Cunha, N.M., Georgousopoulos, E.N., Kellett, J., et al. (2018) Effect of Long-Term

Nutraceutical and Dietary Supplement Use on Cognition in the Elderly: A 10-YearSystematic Review of

Randomized Controlled Trials. British Journal of Nutrition,

119, 280-298. https://doi.org/10.1017/S0007114517003452

[28] Lu, D., Song, H., Hao, Z., et al. (2011) Naftidrofuril for Dementia. Cochrane Database

of Systematic Reviews, No. 12, CD002955.

https://doi.org/10.1002/14651858.CD002955.pub4

[29] McCleery, J., Abraham, R.P., Denton, D.A., et al. (2018) Vitamin and Mineral Supplementation

for Preventing Dementia or Delaying Cognitive Decline in People

with Mild Cognitive Impairment. Cochrane Database of Systematic Reviews, 11,

CD011905. https://doi.org/10.1002/14651858.CD011905.pub2

[30] Singha, A. K., Singla, A., \& Pandey, R. K. (2016). Study and analysis on biometrics and face recognition methods. EPH-International Journal of Science And Engineering (ISSN: 2454-2016), 2(6), 37-41.

[31] Zubair, S., \& Singha, A. K. (2020). Parameter Optimization in Convolutional Neural Networks Using Gradient Descent. In Microservices in Big Data Analytics (pp. 87-94). Springer, Singapore.

[32] Sultana, J., Singha, A. K., Siddiqui, S. T., Nagalaxmi, G., Sriram, A. K., \& Pathak, N. (2022). COVID-19

pandemic prediction and forecasting using machine learning classifiers. Intelligent Automation and Soft Computing, 1007-1024.

[33] Zubair, S., \& Singha, A. K. (2021). Network in Sequential Form: Combine Tree Structure Components into Recurrent Neural Network. In IOP Conference Series: Materials Science and Engineering (Vol. 1017, No. 1, p. 012004). IOP Publishing.

[34] Singha, A. K., Kumar, A., \& Kushwaha, P. K. (2018). Patient Cohort Approaches to data science using Biomedical Field. EPH-International Journal of Science And Engineering (ISSN: 2454-2016), 1(1), 457-462.

[35] Singha, A. K., Kumar, A., \& Kushwaha, P. K. (2018). Classification of brain tumors using deep Encoder along with regression techniques. EPH-International Journal of Science And Engineering (ISSN: 2454-2016), 1(1), 444449.

[36] Singha, A. K., Kumar, A., \& Kushwaha, P. K. (2018). Speed predication of wind using Artificial neural network. EPH-International Journal of Science And Engineering (ISSN: 2454-2016), 1(1), 463-469.

[37] Singha, A. K., Kumar, A., \& Kushwaha, P. K. (2018). Recognition of human layered structure using Gradient decent model. EPH-International Journal of Science And Engineering (ISSN: 2454-2016), 1(1), 450-456.

[38] Nayak, P. K., Mishra, D., \& Ram, S. (2016). Attack of malicious objects in computer network under antivirus and quarantine defence. International Journal of Applied Engineering Research, 11(9), 6250-6253.

[39] Singha, A. K., \& Zubair, S. Enhancing the efficiency of the stochastic method by using non-smooth and nonconvex optimization. 
[40] Cuddy, L.L., et al. (2012) Memory for Melodies and Lyrics in Alzheimer's Disease. Music Perception, 29, 479-491. https://doi.org/10.1525/mp.2012.29.5.479

[41] Platel, H., Baron, J.C., Desgranges, B., Bernard, F. and Eustache, F. (2003) Semantic and Episodic Memory of Music Are Subserved by Distinct Neural Networks. Neuroimage , 20, 244-256. https://doi.org/10.1016/S1053-8119(03)00287-8

[42] Satoh, M., Takeda, K., Nagata, K., Shimosegawa, E. and Kuzuhara, S. (2006) Positron-

Emission Tomography of Brain Regions Activated by Recognition of Familiar

Music. AJNR, 27, 1101-1106.

[43] Jacobsen, J.H., Stelzer, J., Fritz, T.H., Chetelat, G., La Joie, R. and Turner, R. (2015)

Why Musical Memory Can Be Preserved in Advanced Alzheimer's Disease. Brain,

138, 2438-2450. https://doi.org/10.1093/brain/awv135[44] Kongpakwattana, K., Sawangjit, R., Bell, J.S., et al.

(2018) Pharmacological Treatments

for Alleviating Agitation in Dementia: A Systematic Review and Network Meta-

Analysis. British Journal of Clinical Pharmacology, 84, 1445-1456.

https://doi.org/10.1111/bcp.13604

[45] Koger, S.M., Chapin, K. and Brotons, M. (1999) Is Music Therapy an Effective Intervention

for Dementia? A Meta-Analytic Review of Literature. Journal of Music

Therapy, 36, 2-15. https://doi.org/10.1093/jmt/36.1.2

[46] Smith, D.S. (1990) Therapeutic Treatment Effectiveness as Documented in the

Gerontology Literature: Implications for Music Therapy. Music Therapy Perspectives

, 8, 36-40. https://doi.org/10.1093/mtp/8.1.36

[47] Kneafsey, R. (1997) The Therapeutic Use of Music in a Care of the Elderly Setting:

A Literature Review. Journal of Clinical Nursing, 6, 341-346.

https://doi.org/10.1111/j.1365-2702.1997.tb00326.x

[48] Aldridge, D. (1993) Music Therapy Research 1: A Review of the Medical Research

Literature within a General Context of Music Therapy Research. The Arts in Psychotherapy

, 20, 11-35. https://doi.org/10.1016/0197-4556(93)90029-2

[49] Biley, F.C. (2000) The Effects of Patient Well-Being of Music Listening as a Nursing

Intervention: A Review of the Literature. Journal of Clinical Nursing, 9, 668-677.

https://doi.org/10.1046/j.1365-2702.2000.00392.x

[50] Brotons, M., Koger, S.M. and Pickett-Cooper, P. (1997) Music and Dementias: A

Review of Literature. Journal of Music Therapy, 34, 204-245.

https://doi.org/10.1093/jmt/34.4.204

[51] Koger, S.M. and Brotons, M. (2001) Music Therapy for Dementia Symptoms. The

Cochrane Library (Oxford), 4, 1-22.

[52] Lou, M.F. (2001) The Use of Music to Decrease Agitated Behavior of the Demented

Elderly: The State of the Science. Scandinavian Journal of Caring Sciences, 15, 165-

173. https://doi.org/10.1046/j.1471-6712.2001.00021.x

[53] Clair, A.A. (1996) The Effect of Singing on Alert Responses in Persons with Late

Stage Dementia. Journal of Music Therapy, 33, 234-247.

https://doi.org/10.1093/jmt/33.4.234

[54] Thaut, M.H. (1990) Neuropsychological Processes in Music Perception and Their

Relevance in Music Therapy. In: Unkefer, R.F., Ed., Music Therapy in the Treatment

of Adults with Mental Disorders : Theoretical Bases and Clinical Interventions,

Schirmer Books, New York, 3-32.

[55] Clarke, M.E., Lipe, A.W. and Bilbrey, M. (1998) Use of Music to Decrease Aggressive

Behaviors in People with Dementia. Journal of Gerontological Nursing, 24, 10-17.

https://doi.org/10.3928/0098-9134-19980701-05

[56] Thomas, D.W., Heitman, R.J. and Alexander, T. (1997) The Effects of Music on

Bathing Co-Operation for Residents with Dementia. Journal of Music Therapy, 34,

246-259. https://doi.org/10.1093/jmt/34.4.246

[57] Brotons, M. and Pickett-Cooper, P.K. (1996) The Effects of Music Therapy Intervention

on Agitation Behaviours of Alzheimer's Disease Patients. Journal of Music

Therapy, 33, 2-18. https://doi.org/10.1093/jmt/33.1.2

[58] Denney, A. (1997) Quiet Music: An Intervention for Mealtime Agitation? Journal of

Gerontological Nursing, 23, 16-23. https://doi.org/10.3928/0098-9134-19970701-09 
[59] Gerdner, L.A. and Swanson, E.A. (1993) Effects of Individualized Music on Confused and Agitated Elderly Patients. Archives of Psychiatric Nursing, 7, 284-291.

https://doi.org/10.1016/0883-9417(93)90006-I[60] Gerdner, L.A. (2000) Effects of "Individualized" versus

"Relaxation" Music on the

Frequency of Agitation in Elderly Persons with Alzheimer's Disease and Related

Disorders. International Psychogeriatrics, 12, 49-65.

https://doi.org/10.1017/S1041610200006190

[61] Goddaer, J. and Abraham, I.L. (1994) Effects of Relaxing Music on Agitation during

Meals among Nursing Home Residents with Severe Cognitive Impairment. Archives

of Psychiatric Nursing, 8, 150-158.

https://doi.org/10.1016/0883-9417(94)90048-5

[62] Tabloski, P.A., Mckinnon-Howe, L. and Remington, R. (1995) Effects of Calming

Music on the Level of Agitation in Cognitively Impaired Nursing Home Residents.

The American Journal of Alzheimer's Care and Related Disorders \& Research, 10,

10-15. https://doi.org/10.1177/153331759501000105

[63] Groene, R.W. (1993) Effectiveness of Music Therapy 1:1 Intervention with Individuals

Having Senile Dementia of the Alzheimer's Type. Journal of Music Therapy, 30,

138-157. https://doi.org/10.1093/jmt/30.3.138

[64] Casby, J.A. and Holm, M.B. (1994) The Effect of Music on Repetitive Disruptive Vocalizations

of Persons with Dementia. American Journal of Occupational Therapy,

48, 883-889. https://doi.org/10.5014/ajot.48.10.883

[65] Ragneskog, H., Brane, G., Karlsoon, I. and Kihlgren, M. (1996) Influence of Dinner

Music on Food Intake and Symptoms Common in Dementia. Scandinavian Journal

of Caring Sciences, 10, 11-17. https://doi.org/10.1111/j.1471-6712.1996.tb00304.x

[66] Gomez, G.M. and Gomez, G.J. (2017) Music Therapy and Alzheimer's Disease: Cognitive,

Psychological, and Behavioral Effects. Neurologia, 32, 300-308.

https://doi.org/10.1016/j.nrleng.2015.12.001

[67] Sakamoto, M., Ando, H. and Tsutou, A. (2013) Comparing the Effects of Different

Individualized Music Interventions for Elderly Individuals with Severe Dementia.

International Psychogeriatrics, 25, 775-784.

https://doi.org/10.1017/S1041610212002256

[68] Smith-Marchese, K. (1994) The Effects of Participatory Music on the Reality, Orientation

and Sociability of Alzheimer's Residents in a Long-Term Care Setting. Activities

, Adaptation and Aging, 18, 41-55. https://doi.org/10.1300/J016v18n02_04

[69] Lord, T.R. and Garner, J.E. (1993) Effects of Music on Alzheimer's Patients. Perceptual

and Motor Skills, 76, 451-455. https://doi.org/10.2466/pms.1993.76.2.451

[70] Ragneskog, H., Kihlgren, M., Karlsoon, I. and Norberg, A. (1996) Dinner Music for Demented Patients: Analysis of Video Recorded Observations. Clinical Nursing Research, 5, 262-282. https://doi.org/10.1177/105477389600500302

[71] Clair, A.A., Bernstein, B. and Johnson, G. (1995) Rhythm Playing Characteristics in Persons with Severe Dementia Including Those with Probable Alzheimer's Type.

Journal of Music Therapy, 32, 113-131. https://doi.org/10.1093/jmt/32.2.113

[72] Olderog-Millard, K.A. and Smith, J.M. (1989) The Influence of Group Singing Therapy

on the Behavior of Alzheimer's Disease Patients. Journal of Music Therapy, 26,

58-70. https://doi.org/10.1093/jmt/26.2.58

[73] Pollack, N. and Namazi, K.H. (1992) The Effect of Music Participation on the Social

Behavior of Alzheimer's Disease Patients. Journal of Music Therapy, 29, 54-67.

https://doi.org/10.1093/jmt/29.1.54

[74] Snyder, M. and Olson, J. (1996) Music and Hand Massage Interventions to Produce

Relaxation and Reduce Aggressive Behaviors in Cognitively Impaired Elders: A Pilot

Study. Clinical Gerontologist, 17, 64-69.

[75] Clair, A.A. and Bernstein, B. (1994) The Effect of No Music, Simulative BackgroundMusic and Sedative

Background Music on Agitated Behaviors in Persons with Severe

Dementia. Activities, Adaptation and Aging, 19, 61-70.

https://doi.org/10.1300/J016v19n01_05

[76] Brotons, M. and Marti, P. (2003) Music Therapy with Alzheimer's Patients and 
Their Family Caregivers: A Pilot Project. Journal of Music Therapy, 40, 138-150. https://doi.org/10.1093/jmt/40.2.138

[77] Leggieri, M., Thaut, M.H., Fornazzari, L., et al. (2019) Music Intervention Approaches forAlzheimer's Disease: A Review of the Literature. Frontiers in Neuroscience, 12, 130-132. https://doi.org/10.3389/fnins.2019.00132

[78] Kolsch, S. (2009) A Neuroscientific Perspective on Music Therapy. The Neurosciences and Music III Disorders and Plasticity : Annals of the New York Academy of

Sciences, 1169, 374-384. https://doi.org/10.1111/j.1749-6632.2009.04592.x

[79] Kobets, A.J. (2011) Harmonic Medicine: The Influence of Music over Mind and Medical Practice. Yale Journal of Biology and Medicine, 84, 161-167. 